\title{
The Steady-State Performance of a Controlled Current Active Filter
}

\author{
Richard M. Duke, Member, IEEE, and Simon D. Round, Student Member, IEEE
}

\begin{abstract}
An active filter that uses a high-frequency $D$-class asynchronous switching inverter for power system current distortion compensation is described. The distortion compensation technique involves deriving a signal corresponding to the distortion component of load current, and inverting and amplifying this signal for addition back to the supply current to cancel the load current distortion. A synthetic sinusoid is used to determine the distortion component in the time domain. Extensive computed and experimental results, illustrating the system's steadystate performance and ability to reduce the current harmonic distortion components, are presented. An intelligent controller is proposed to maintain the active filter's performance at the optimal operating point under varying load conditions.
\end{abstract}

\section{INTRODUCTION}

$\mathbf{T}$ RADITIONALLY, the majority of power consumption has been drawn by linear loads such as incandescent lighting, heating, and ac motors. This situation is rapidly changing as more products are being developed that condition the power through the use of power electronic devices. These power electronic devices are now able to process large amounts of power, and their advantages, increased efficiency and ease of control, have caused a dramatic increase in the number of power electronic loads. Unfortunately, power electronic loads have an inherently nonlinear nature, and they therefore draw a distorted current from the mains supply.

The detrimental effects of load current distortion can be solved if the distortion or harmonic components of the load current are removed, leaving a "clean" sinusoidal supply current. Traditionally, the unwanted harmonic distortion components have been removed by the use of passive filters. However, passive filters are nonselective, so they not only filter out the unwanted harmonic components from the supply on which they are installed, but they also serve as a "sink" for the distortion components produced by other consumers in the vicinity. They are also generally tuned to remove specific frequency components, and are therefore not a completely satisfactory solution when the harmonic composition of the distorted waveform changes.

In recent publications, a wide range of active filtering techniques has been proposed [1]-[7]. These active filtering techniques include the use of both voltage source (VSI) [1], [2] and current source inverters [3]-[5]. Akagi et al.

Manuscript received February 20, 1991; revised December 30, 1992.

R. M. Duke is with the Department of Electrical and Electronic Engineering, University of Canterbury, Christchurch, New Zealand.

S. D. Round is with the Department of Electrical Engineering, University of Minnesota, Minneapolis, MN 55455.

IEEE Log Number 9207859.
[1] describe an active filter using multiple voltage source inverters and a time-delay PWM switching strategy. A followup paper [2] details the control circuit, which is based on instantaneous reactive power theory, and performance for the transient response of the active filter. Enslin et al. [3] determine the compensation current by deriving the deactive power of the load. The compensating current is then reinjected by a current source inverter. Hayafune et al. [4] describe the use of a computer to generate the switching signals to achieve the correct compensation current. Computation of the compensating current using the techniques described by Enslin and Hayafune require extensive computer processing. Other authors have described what could be termed more traditional power system techniques, such as the use of cycloconverters, to generate the compensating current [6], [7].

An active filtering technique using a high-frequency VSI and a time-delay switching strategy is described in this paper. The switching strategy produces an inverter output current which is asynchronous, unlike the more traditional fixed frequency PWM techniques [5]. The required compensating current is determined using a simple synthetic sinusoid generation technique. This compensating current is produced in real time, and is not delayed by any computer processing required to calculate the Fourier components of load current as described in [4] and [6]. Detailed experimental and computer simulated steady-state performance and operational characteristics of the active filter are presented. On the basis of the measured and simulated performance data, an intelligent controller which determines the optimum operating point of the active filter is proposed.

\section{THE ACTIVE FILTERING SYSTEM}

The active filtering system is based on a philosophy that addresses the load current distortion from a time domain rather than a frequency domain approach [8]. The most effective way to improve the distortive power factor in a nonsinusoidal situation is to use a nonlinear time-varying active device that directly compensates for the load current distortion. The system, which employs a controlled current VSI, is shown in Fig. 1.

The load current $\left(I_{L}\right)$ is comprised of fundamental and distortion components drawn by the nonlinear load. Using a current transducer, a sinusoid corresponding to the fundamental component of $I_{L}$ is extracted by the signal processing unit (SPU) (Fig. 2). Analog circuitry is used to determine the phase and magnitude of the load current fundamental component. A bandpass filter, with minimal phase delay, is used in the 


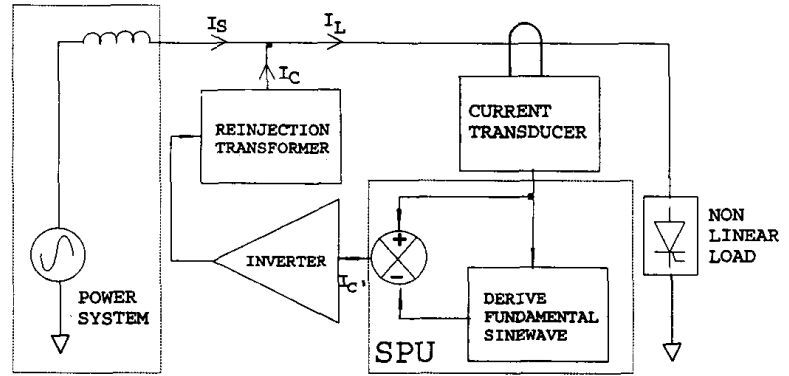

Fig. 1. Active filtering system.

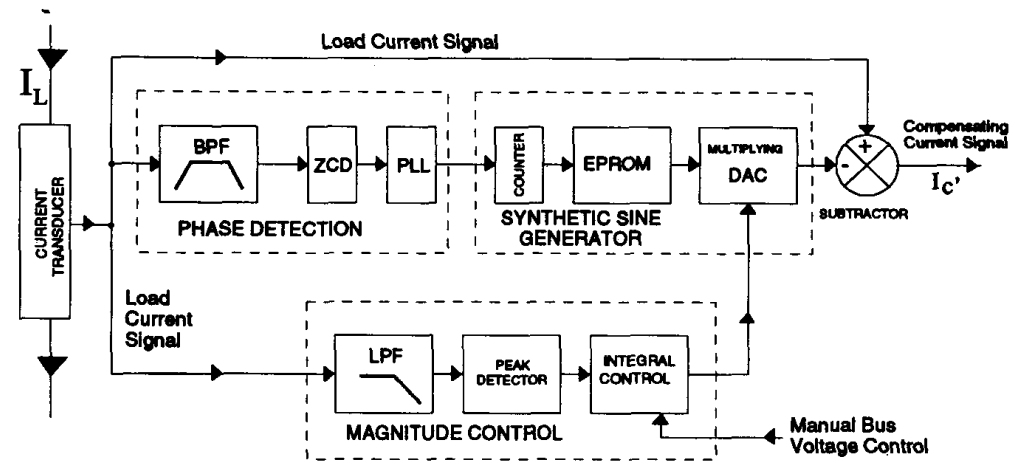

Fig. 2. Signal processing unit.

phase detection circuit to determine the zero crossings (ZCD) of the load current fundamental. Any shift of the zero crossings alters the frequency of the phase-locked loop (PLL) so that it tracks the changes in fundamental frequency. The fundamental component of $I_{L}$ is synthetically generated by clocking the waveform out of an EPROM and a digital-to-analog converter (DAC) at a rate determined by the PLL. The magnitude control circuitry determines the amplitude of the synthetic sinusoid produced from the multiplying DAC. The amplitude of the load current's fundamental is obtained by low-pass filtering and peak detecting the load current waveform. To compensate for the inverter losses, the amplitude of the synthetic sinusoid is increased. Real power now flows into the inverter bus capacitor. Any excess power over and above that required to provide compensation for the losses will increase the inverter dc bus voltage. Thus, the inverter dc bus voltage can be controlled by manipulating the amplitude of the synthetic sinusoid.

Subtraction of this synthetic sinusoid (fundamental component) from $I_{L}$ leaves the distortion component of load current $\left(I_{C^{\prime}}\right)$, which is then amplified by the controlled current inverter (Fig. 1) to form the compensating current. This compensating current $\left(I_{C}\right)$ is added to the supply via a reinjection transformer, which results in distortion current cancellation and a nearly sinusoidal supply current $\left(I_{S}\right)$.

Fig. 3 shows a typical nonlinear load current $\left(I_{L}\right)$ signal extracted by the current transducer, the fundamental component of $I_{L}\left(I_{L f}\right)$ extracted by the SPU, and the compensating current $\left(I_{C^{\prime}}\right)$ signal required to drive the controlled current inverter and produce a sinusoidal supply current.

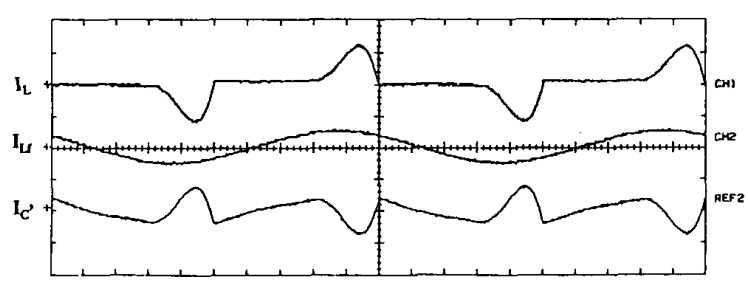

Fig. 3. Control signals.

\section{Mathematical MODEL}

The switching operations of the controlled current inverter cannot be prespecified. Therefore, a dynamic modeling technique, such as state-space analysis, is necessary. Using the branch formulation developed for modeling thyristorcontrolled circuits [9] and modifying that formulation to include capacitive branches [10], a general state-space formulation

$$
\begin{aligned}
& \dot{\boldsymbol{x}}(\boldsymbol{t})=\boldsymbol{A x}(\boldsymbol{t})+\boldsymbol{B u}(t) \\
& \boldsymbol{y}(t)=C \boldsymbol{x}(\boldsymbol{t})+\boldsymbol{D u}(t)
\end{aligned}
$$

can be written. Inductor currents and capacitor voltages are contained in the state vector $\boldsymbol{x}(\boldsymbol{t}) \cdot \boldsymbol{u}(\boldsymbol{t})$ is the vector of voltage sources, and $\boldsymbol{y}(\boldsymbol{t})$ is the output vector of node voltages and branch currents. Since the simulation of power electronic switching circuits involves a piecewise linear approximation of the actual circuit, $\boldsymbol{A}, \boldsymbol{B}, \boldsymbol{C}$, and $\boldsymbol{D}$ matrices must be determined for each different component interconnection. As a consequence, a number of state-space models are required, 


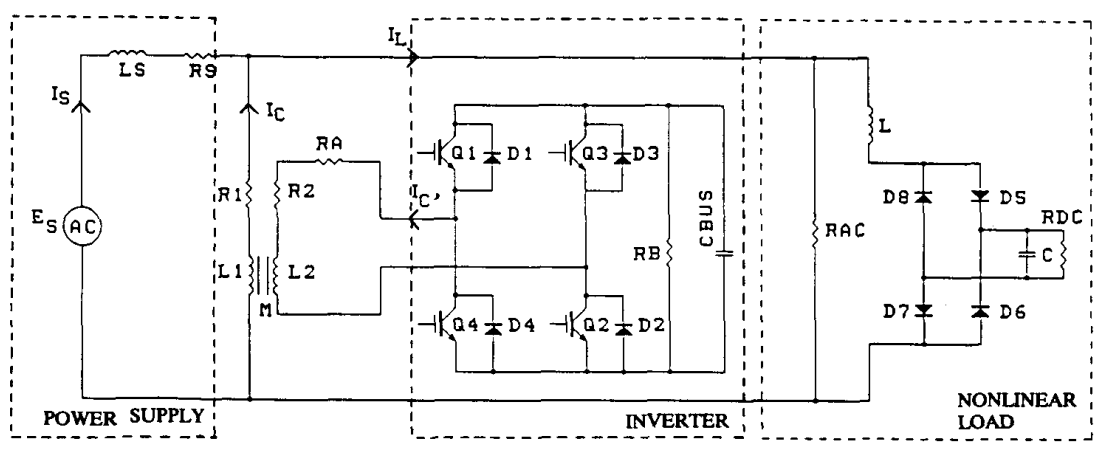

Fig. 4. Computer model.

the number depending on the complexity of the circuit under investigation. The computer simulation has been implemented using the scientific and matrix-based package MATLAB.

The computer model of the active filtering system is shown in Fig. $4, E_{s}, L_{s}$, and $R_{s}$ represent the supply voltage and impedance, respectively. The reinjection transformer is represented by $R_{1}, L_{1}, R_{2}, L_{2}$, and mutual inductance $M$. Resistor $R_{A}$ represents the sum of the transistor "ON" resistance and the bus capacitor's ( $C_{\mathrm{BUS}}$ ) equivalent series resistance. $R_{B}$ represents the power consumed by the control circuitry and by the voltage clamping circuitry. The nonlinear load consists primarily of an undistorted base load combined with a typical rectifier load. Each of the transistors $Q 1-Q 4$ and diodes $D 1-D 8$ is modeled as a switch.

Considering the inverter, there are four possible configurations. The following pairs of switches may be conducting: $Q 1$ and $Q 2, Q 3$ and $Q 4, D 1$ and $D 2, D 3$ and $D 4$. In combination with the three possible load circuit configurations (either $D 5$ and $D 7$ or $D 6$ and $D 8$ conducting, or neither $D 5, D 6, D 7$ nor $D 8$ conducting), the total number of circuit configurations is thus 12. However, since the circuit topology is identical when either one pair of transistors is conducting (say $Q 1$ and $Q 2$ ) or when their bypass diodes are conducting ( $D 1$ and $D 2$ ), only six circuit configurations are required for computer modeling.

With reference to the transistor switching diagram (Fig. 5), the topological model changes (transistor switching instants) are determined in the following way. Assuming that the actual inverter output current is greater than the compensating current signal (point $A$ ), the simulation, using the appropriate circuit model, is allowed to run until the actual inverter output current is less than the compensating current signal (point $B$ ). Linear interpolation is then used to determine the exact crossing instant (point $C$ ). The simulation is restarted from this time and allowed to run for a set time $(t \mu \mathrm{s})$. This time delays the transistor switching instant until point $D$ and determines the average switching frequency $\left(f_{\mathrm{av}} \approx\right.$ $1 / 4 t$ ) of the inverter. At point $D$, the circuit topology is changed, and the simulation runs until the next crossing (point $E$ ) can be determined. Restarting from point $E$, the simulation runs for a further $t \mu \mathrm{s}$ until it reaches point $F$. This pattern of simulation, linear interpolation, simulation, and model changing continues, producing the appropriate compensated supply current waveform.

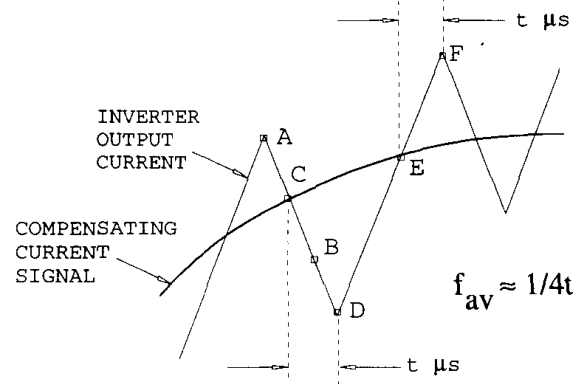

Fig. 5. Transistor switching diagram.

\section{COMPUTER Simulation}

The power supply for the active filter and nonlinear load is a single-phase $240 \mathrm{~V}, 50 \mathrm{~Hz}$ system, and the load, as shown in Fig. 4, consists of a base sinusoidal load rated $500 \mathrm{~W}$ and drawing $2.2 \mathrm{~A} \mathrm{rms}$, together with a typical nonlinear rectifier load rated $370 \mathrm{~W}$ and delivering $1 \mathrm{~A}$ dc. The bus capacitance $\left(C_{\mathrm{BUS}}\right)$ is $1880 \mu \mathrm{F}$ and the reinjection transformer has a ratio of 2:1. The time delay $t$ (Fig. 5) is set to $10 \mu \mathrm{s}$, and an average bus voltage of $260 \mathrm{~V} \mathrm{dc}$ is maintained.

The results of the computer simulation, illustrating the compensated supply and load currents and compensating current, are shown in Fig. 6(a) and (b), respectively. The variability of the switching frequency is evident from Fig. 6(b). The variation of the capacitor bus voltage shown in Fig. 6(c) illustrates the bidirectional power flow through the inverter. As the compensating current magnitude tends towards zero, the bus voltage rises, and conversely, as the compensating current tends away from zero, the bus voltage falls.

The frequency spectra of the computed compensated supply current and load current are shown in Fig. 6(d). A comparison of these figures shows that the third harmonic has fallen to $45 \mathrm{~dB} \cdot \mathrm{V}$ below the fundamental $(0.56 \%$ of the fundamental $)$ after compensation. All other harmonics also show a reduction in amplitude, and these spectra give an indication of the ideal performance that could be expected from the active filter.

The asynchronous switching nature of the active filter, as noted in Fig. 6(b), is also illustrated by Fig. 6(e), which shows the distribution of switching frequencies for this particular load. The predominant switching frequency is $24 \mathrm{kHz}$, al- 


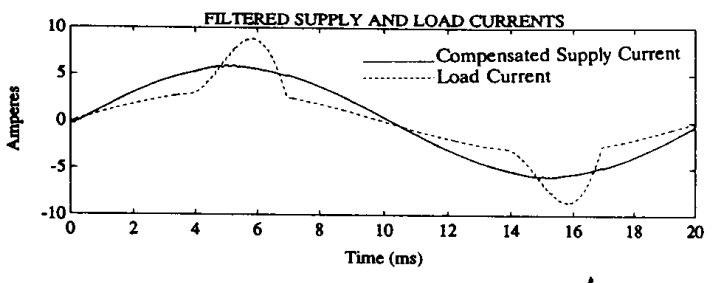

(a)

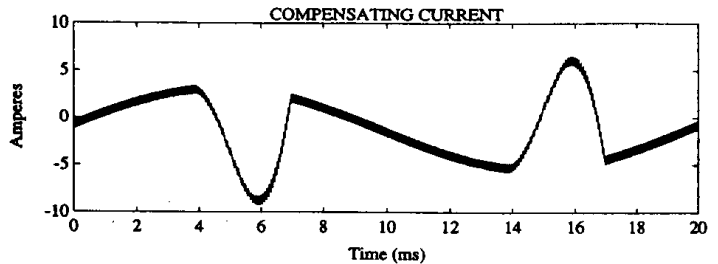

(b)

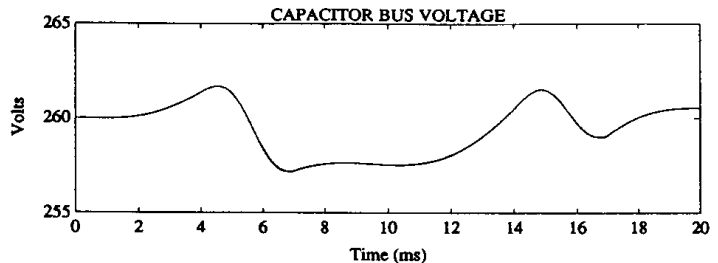

(c)

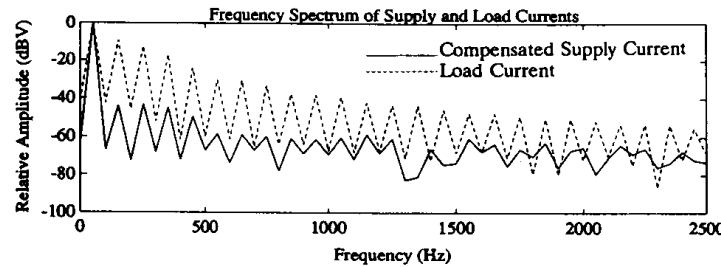

(d)

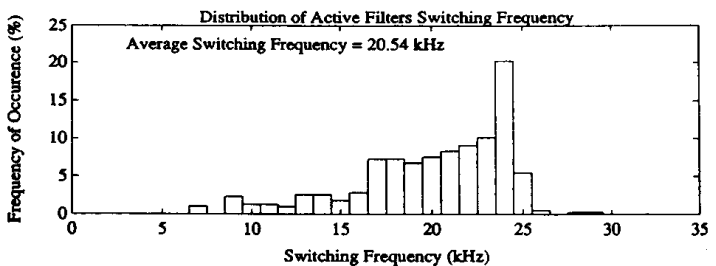

(e)

Fig. 6. Computed steady-state results.

though the switching frequency does fall as low as $7 \mathrm{kHz}$ and rises as high as $29 \mathrm{kHz}$.

\section{EXPERIMENTAL VERIFICATION}

The active filtering technique has been evaluated using a single-phase prototype circuit that provides up to $2 \mathrm{kVA}$ of harmonic distortion compensation. The nonlinear load and single-phase power supply match those used in the computer simulation discussed in the previous section. The $D$-class switching inverter is interfaced to the power supply via a reinjection transformer of ratio $2: 1$. The switching strategy is the same as for the computer simulation, and the time delay $t$ is set to $10 \mu \mathrm{s}$. The amplitude of the synthetic sinusoid (fundamental component of $I_{L}$ ) is adjusted to achieve a dc bus voltage of $260 \mathrm{~V} \mathrm{dc}$. The inverter output current is sensed using a resistor $(R)$, and the comparison of this signal with the compensating current signal takes place referenced to the inverter output (Fig. 7). To avoid isolation problems, the control logic and inverter current-sensing resistor $R$ are both referenced to the emitter of one of the inverter transistors. The resistor $R$ has an excellent response, giving a voltage proportional to the instantaneous inverter output current. A simple signal transformer is used to provide isolation between the signal processing circuitry and the comparison circuitry since the compensating signal frequency is considerably less than the switching output current waveform. The inverter control logic activates either of the two diagonal pairs of transistors, to apply a positive or negative voltage across the load. Current in the load then ramps up or down at a rate determined by the time constant of the load.

The prototype inverter uses the recently developed insulated gate bipolar transistors (IGBT) [11] rated at $1200 \mathrm{~V}, 25 \mathrm{~A}$. These devices, like MOSFET's, are voltage-controlled, allowing the use of low power drive circuitry. IGBT's can switch at higher frequencies than conventional bipolar transistors, and therefore offer the possibility of investigating a wide range of inverter operating frequencies $(2-40 \mathrm{kHz})$. IGBT's also offer lower on-state losses than similarly rated MOSFET's.

The distortion of the load current $I_{L}$ is evident from Fig. 8(a), and the measured total harmonic distortion (THD), taking into account frequencies up to $1050 \mathrm{~Hz}$, is $42.1 \%$. The compensating current $I_{C}$ is shown in Fig. 8(b), and the variability of the switching frequency is apparent, just as it was in the computed waveform Fig. 6(b). The compensated supply current $I_{S}$, shown in Fig. 8(c), is now nearly sinusoidal, and the THD has been reduced to $2.6 \%$.

A close examination of the compensated supply current reveals that notches appear at the time the rectifier load turns off. These notches have occurred because the response of the inverter is not ideal, it is limited by the leakage inductance of the reinjection transformer, and cannot accurately track the discontinuity in current caused by the turn off of the rectifier load. Near the peak of the compensated supply current, a number of small ripples occur. These ripples are due to the fast rate of change of the compensating current producing low-frequency switching. These notches and ripples are also apparent in the computed compensated supply current, but because of the scale of the waveform, are not so obvious.

Fig. 8(d) and (e) shows the measured spectra of the load current and the compensated supply current, respectively. From a comparison of these spectra, it can be seen that with compensation, the third harmonic $(150 \mathrm{~Hz})$ has fallen $23 \mathrm{~dB}$. $\mathrm{V}$ and the fifth harmonic $(250 \mathrm{~Hz})$ has fallen $27 \mathrm{~dB} \cdot \mathrm{V}$. The third harmonic of the compensated supply current is now 35 $\mathrm{dB}$. V below the fundamental ( $1.78 \%$ of the fundamental). This compares with the ideal computed results, which indicate that the third harmonic's amplitude must be at least $0.56 \%$ of the fundamental. 


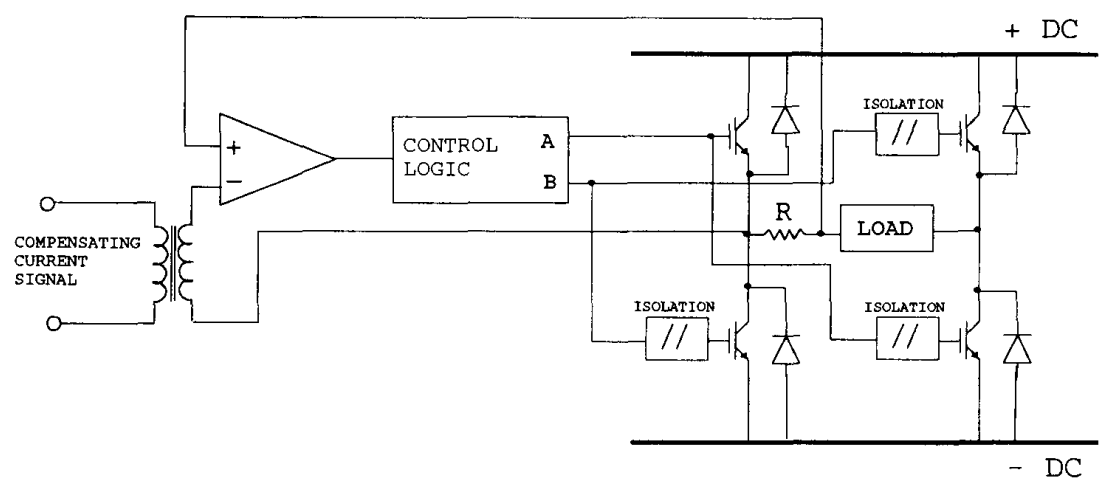

Fig. 7. Inverter switching control.

\section{PERFORMANCE}

The performance of the active filter can be judged by its ability to reduce the harmonic content of the supply current for a typical nonlinear load. The THD of the supply current can be used as a figure of merit no matter what the harmonic composition of the load current is. This level of THD can be altered by changing the operating conditions (switching frequency and dc bus voltage) of the active filter; however, this is at the cost of also altering the operating efficiency of the system. For each particular nonlinear load and dc bus voltage combination, there is an optimum switching frequency range over which minimization of the THD of the supply current can be achieved while maximizing operating efficiency.

Fig. 9(a) and (b) shows the effect of bus voltage variation on the switching frequency profiles for a switching time delay of $15 \mu \mathrm{s}$ (average switching frequency of $16 \mathrm{kHz}$ ). Increasing the capacitor bus voltage from 190 to $350 \mathrm{~V}$ dc shows a decrease in the lower frequency components and a slight increase in the higher frequency components. The low-frequency components $(2-10 \mathrm{kHz})$ at a bus voltage of $190 \mathrm{~V} \mathrm{dc}$ have been shifted above $10 \mathrm{kHz}$ when the bus voltage is increased to $350 \mathrm{~V}$ dc. This is explained by considering the rate of rise of current through the reinjection transformer. The bus voltage to leakage inductance ratio governs this rate of rise of current. When the bus voltage is increased, this effectively increases the rate of rise of current, and the average switching frequency increases, allowing the active filter to more closely follow faster changing waveforms.

Operating efficiency of the active filter is based on the real power flow in the system, and is determined from the fundamental current that is in phase with the supply voltage. Assuming that the load and active filter is supplied from a strong ac system, the real power flow is the product of the voltage and in-phase fundamental current component. The efficiency $(\zeta)$ of the compensation system can then be defined by

$$
\zeta=\frac{P_{\text {load current }}}{P_{\text {supply current with compensation }}} .
$$

Fig. 10(a) shows the measured efficiency of the active filter with different average switching frequencies and dc bus voltages. The efficiency of the active filter improves with

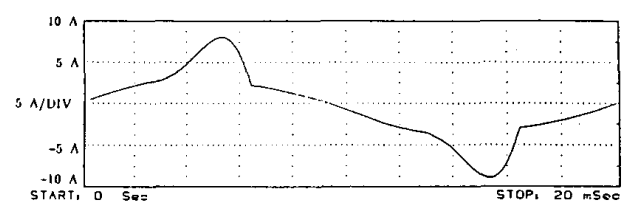

(a)

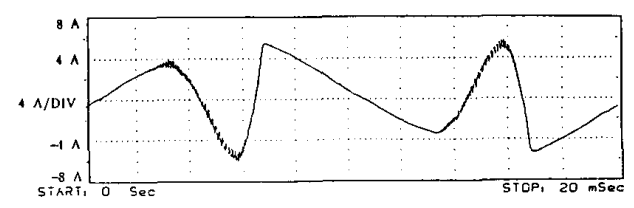

(b)

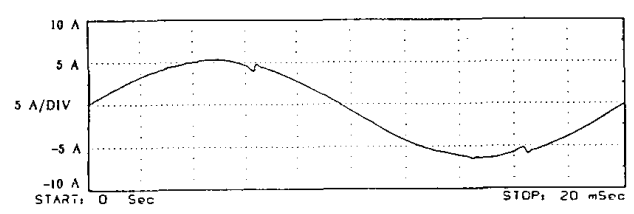

(c)

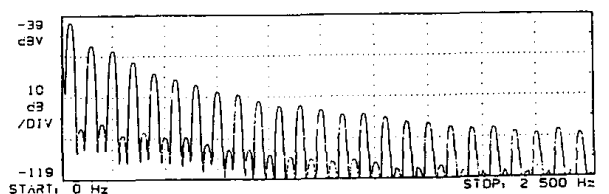

(d)

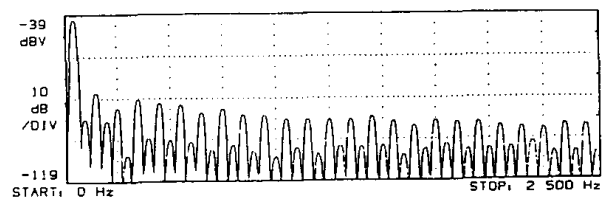

(e)

Fig. 8. Experimental steady-state results. (a) Load current. (b) Compensating current. (c) Compensated supply current. (d) Load current spectrum. (e) Compensated supply current spectrum.

low bus voltages because the rate of rise of current has decreased. The switching frequency profile now contains a greater proportion of lower frequency components. Hence, the switching losses decrease because the inverter is switching at 


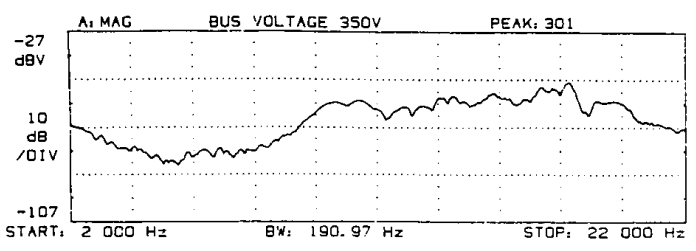

(a)

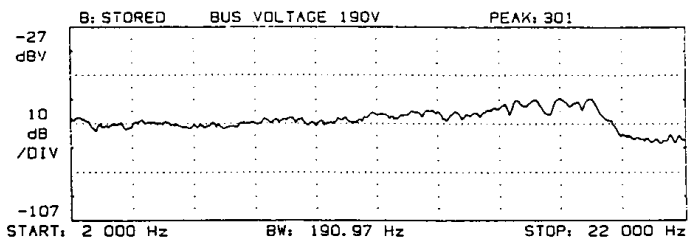

(b)

Fig. 9. Switching frequency profiles.

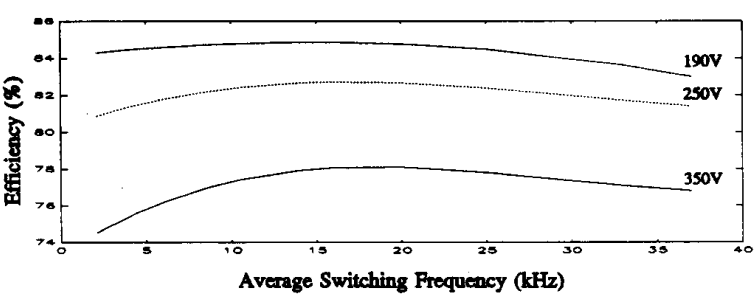

(a)

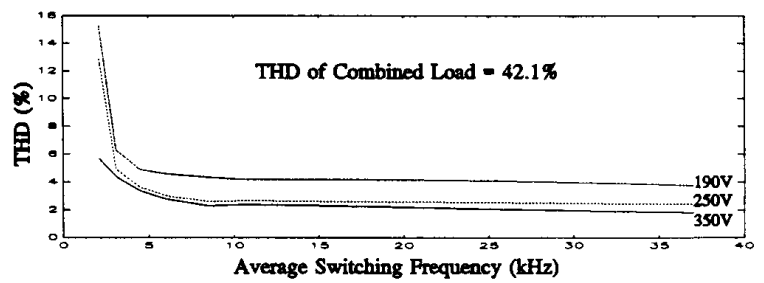

(b)

Fig. 10. Measured performance. (a) Efficiency of the active filter with a combined load. (b) Supply THD of the active filter with a combined load.

a lower average frequency and a lower bus voltage is applied across the semiconductors. As the bus voltage is increased, at the same switching time delay, the semiconductor switching losses increase significantly and efficiency decreases. At low frequencies (less than $5 \mathrm{kHz}$ ), the current excursions are increased, and the conduction losses of the system are dominant. At high switching frequencies (greater than $20 \mathrm{kHz}$ ), the switching losses of the system become more dominant, and thus the efficiency tends to fall. The most efficient average switching frequency for this particular nonlinear load is in the range $17-20 \mathrm{kHz}$. To establish an appropriate bus voltage operating level, the THD performance of the active filter must also be considered.

The measured level of supply current THD at various bus voltages and average switching frequencies is shown in Fig. 10(b). At low bus voltages, the THD performance is poor because the dc bus has insufficient stored energy to reinject enough compensating current for complete harmonic cancellation. By increasing the bus voltage, the system can better compensate for the harmonic distortion; however, the incremental increase in THD at higher bus voltages is small. The other factor that can alter the THD performance is the average switching frequency. At low switching frequencies (less than $7 \mathrm{kHz}$ ), the THD is up to three times larger than that achieved at higher frequencies. The reason for this trend is that at low frequencies, the inverter output current does not closely follow the compensating current signal, and thus the harmonic compensation is less then ideal. As the frequency increases, the inverter output current can follow the required compensating current signal far more closely, and thus the harmonic content can be further reduced.

Another consideration is the audible noise the switching inverter produces. Ideally, the average switching frequency should be chosen to be outside the audible range of humans. Thus, an optimum operating region for the active filter can be selected by choosing an average switching frequency of at least $20 \mathrm{kHz}$ and a bus voltage of $230 \mathrm{~V} \mathrm{dc}$. This would produce a level of $2.6 \%$ THD in the supply current, a reduction from $42.1 \%$, and the system would be operating at an efficiency of $83.6 \%$. Because of the dominance of transformer and other device losses, the efficiency of this low-power prototype is less than would normally be expected from a typical commercial implementation.

\section{Discussion}

The active filter system uses a switching strategy that is not fixed in frequency, but is asynchronous by nature. The optimal operating region (choice of average switching frequency and dc bus voltage) for various loads will be unknown and cannot be calculated. As an aid to establishing this optimum operating region, computer simulations have proved useful for initially determining a minimum average switching frequency to achieve a desired level of THD. To determine the appropriate optimum operating region for a wide selection of load types would require some form of intelligent controller. Such a controller would require information on THD and efficiency, with restrictions on switching frequencies and dc bus voltages. Therefore, an intelligent controller, which monitors the efficiency and THD and alters the operating point to achieve optimal performance, is proposed. To achieve realtime operation, a TMS320C30 digital signal processor (DSP) has been chosen as the controller.

Development for higher voltage three-phase systems is easily catered for by using three single phase units, one for each phase. This will allow different distortion compensations to be applied to each phase for unbalanced three-phase loads. Present transistor technology should allow up to about 500 kVA of harmonic cancellation power to be reinjected.

The system can be configured to provide only distortion current compensation, as discussed in this paper, or can also include phase angle correction by phase shifting the EPROM generated fundamental sinusoid. The active filter could also easily be combined with passive filters to achieve an optimal economic solution to power system filtering applications.

Although this paper is specifically concerned with the steady-state performance of the active filter, some brief com- 
ments regarding transient performance would be appropriate. Transient operation of the active filter is mainly dependent on the two following conditions: how closely the synthetic sinusoid's generation can follow the changing load current's fundamental component, and the rate of rise of current through the reinjection transformer. Presently, the analog magnitude control circuitry takes $100 \mathrm{~ms}$ to compensate for a step change in load current. To compensate for a step increase in load current during the transient period, extra energy from the $\mathrm{dc}$ bus capacitors is required. Therefore, the voltage on the dc bus capacitors falls, resulting in the active filter not being able to provide full compensation. Thus, the ability to quickly detect load current changes and adjust the amplitude of the synthetic sinusoid is a requirement for a fast transient response. This requirement can be implemented in a DSP-based controller with the advantage that more intelligent transient control can be performed under various loads. The limitation on the reinjection transformer can be overcome by using a lower leakage transformer.

\section{CONCLUSION}

It has been demonstrated, both experimentally and by computer simulation, that an active filtering system using a highfrequency asynchronously controlled current inverter is effective in reducing the harmonic content of distorted current waveforms. The novel use of a digitally generated sinewave in the SPU has provided an effective means for deriving the required compensating signal for any arbitrary load current waveform. There is an optimum operating range for the active filter which is determined by the choice of average switching frequency and dc bus voltage of the inverter.

Results show that for a sample nonlinear load, the active filter operates at an efficiency of $83.6 \%$ while switching at an average frequency of $20 \mathrm{kHz}$. The supply current lower order harmonics (third, fifth, and seventh) are all reduced to a level of at least $35 \mathrm{~dB}$. V below the fundamental and the THD is reduced from 42.1 to $2.6 \%$.

\section{REFERENCES}

[1] H. Akagi, A. Nabae, and S. Atoh, "Control strategy of active power filters using multiple voltage-source PWM converters," IEEE Trans. Ind Appl., vol. IA-22, no. 3, pp. 460-465, 1986.
[2] F. Z. Peng, H. Akagi, and A. Nabae, "A study of active power filters using quad-series voltage-source PWM converters for harmonic compensation," IEEE Trans. Power Electron., vol. 5, no. 1, pp. 9-15, 1990.

[3] J. H. R. Enslin and J. D. Van Wyk, "A new control philosophy for power electronic converters as fictitious power compensators," IEEE Trans. Power Electron., vol. 5, no. 1, pp. 88-97, 1990.

[4] K. Hayafune, T. Ueshiba, E. Masada, and Y. Ogiwara, "Microcomputer controlled active power filter," in IEEE IECON Proc., 1984, pp $1221-1226$.

[5] Y. Hayashi, N. Sato, and K. Takahashi, "A novel control of a currentsource active filter for $\mathrm{AC}$ power system harmonic compensation," IEEE Trans. Ind. Appl., vol. 27, no. 2, pp. 380-385, 1991.

[6] R. Fisher and R. Hoft, "Three-phase power line conditioner for harmonic compensation and power factor correction," in IEEE-IAS Conf. Proc. 1987, pp. 803-807.

[7] S. Madangopal and J. J. Cathey, "Suppression of converter introduced harmonic currents using a forced-commutated cycloconverter," IEEE Trans. Energy Conv., vol. 5, no. 4, pp. 632-639, 1990.

[8] K. C. Henderson, "The development of an active harmonic filter for power systems," in Proc. IPENZ Annu. Conf., vol. II, 1990, pp. 129-138.

[9] J. Arrillaga and R. M. Duke, "A static alternative to the transformer on-load tap-changer," IEEE Trans. Power App. Syst., vol. PAS-99, no. 1, pp. 86-91, 1980.

[10] R. M. Duke, S. D. Round, and K. C. Henderson, "An active filter for current distortion compensation in power systems," in Proc. 4th Conf Harmonics in Power Syst., Budapest, Hungary, Oct. 1990, pp. 367-373.

[11] B. J. Baliga, Modern Power Devices. New York: Wiley, 1987

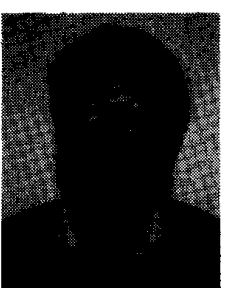

Richard M. Duke (S'75-M'79) received the B.Sc degree in mathematics, and the B.E. (Hons.), M.E. and Ph.D. degrees in electrical engineering from the University of Canterbury, Christchurch, New Zealand, in $1965,1973,1976$, and 1979 , respectively.

$\mathrm{He}$ worked as an Engineer with the New Zealand Electricity Department. Since 1984 he has held a lecturing position at the University of Canterbury, where he is currently a Senior Lecturer in the Department of Electrical and Electronic Engineering. His research interests include power electronics and power system harmonics.

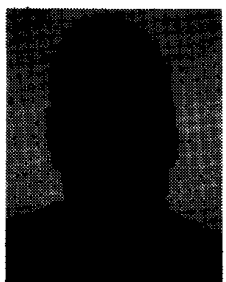

Simon D. Round (S'87) received the B.E. (Hons.) and Ph.D. degrees from the University of Canterbury, Christchurch, New Zealand, in 1989 and 1993 respectively.

He currently holds the position of Research Associate in the Department of Electrical Engineering at the University of Minnesota, Minneapolis. His current area of research is the investigation of neura networks and intelligent controllers for active filters and other power electronic systems. 